\title{
Determination of heavy metals in some cosmetics available in locally markets
}

\author{
Nibras Mohammed alsaffar ${ }^{1}$, Huda jabber Hussein ${ }^{2}$ \\ ${ }^{1,2}$ (Market research center and consumer protection/University of Baghdad/Iraq)
}

\begin{abstract}
It has been shown that heavy metals toxicity to humans is as a result of long term or high level exposure to pollutants common in the environment including the air, water, food and numerous consumer products such as the cosmetics and toiletries. In this study, we assessed the levels of toxic metals in different cosmetic products sold at local shops in Baghdad. The cosmetic items included Eye Shadow. These items were purchased from various shops at different locations in Baghdad. The cosmetics were analyzed for heavy metals (Copper, cadmium, lead, and nickel) after digestion with concentrated acids HNO3: HCl in ratio 1:3. The concentrations of the selected toxic heavy metals were determined in duplicate using aflame atomic absorption spectrophotometer. The samples analyzed contained a detectable amount of the metals of interest. The concentration of the heavy metals in the samples ranged from 0.092 to $25.57 \mathrm{ppm}$. It is obvious from the present study that the use of some cosmetic products exposes users to low concentrations of toxic heavy metals which could constitute potential health risk to users since it has been known that heavy metals can accumulate in the biological system over time and are known to induce skin problems or diseases such as cancer. Further research to better understand the sources of heavy metals in cosmetic product is recommended.

Keywords: cosmetics, Heavy metal, Eye shadow.
\end{abstract}

\section{Introduction}

A cosmetic product is any substance or preparation intended to be placed in contact with the various external parts of the human body (epidermis, hair system, nails, lips and external genital organs) or applied to the teeth and the mucous membranes of the oral cavity with a view exclusively or mainly for the purpose of cleaning, perfuming, protection, changing their appearance, correcting body odors' and keeping the surfaces in good condition [1,2]. Cosmetics are mixtures of some surfactants, oils and other ingredients and are required to be effective, long-lasting, stable and safe to human use The various forms of cosmetic include lipstick and lip gloss (used to color the lips); powder, and rouge (used to color the face, lightening and removing flaws to produce an impression of health and youth); mascara (used to enhance the eye lashes, eye liner and eye shadow (used to color the eye lids); and nail polish (used to color the fingernails and toenails[3]. There is a general belief that even with the regulation of many cosmetic products, there are still health concerns regarding the presence of harmful chemicals within these products. Aside from color additives, cosmetic products and their ingredients are not subject to Food and Drug Administration (FDA) regulation prior to their release into the market. It is only when a product is found to violate Federal Food, Drug, and Cosmetic Act (FD\&C Act) and Fair Packaging and Labeling Act (FPLA) after its release that the FDA may start taking action against this violation. With many new products released into the market every season, it is hard to keep track of the safety of every pro-duct and some products may carry carcinogenic contaminant [4].Many cosmetic products contain heavy metals such as lead, arsenic, mercury, cobalt, and nickel as ingredients or impurities. Recent research has reported that these metals can easily cause many types of skin problems [5,6].The use of some heavy metals in cosmetic has been controversial due to the biological accumulation of those metals and their toxicity in the human body. In most countries, it is legally prohibited to use lead, arsenic, and mercury in skin cosmetic products for example; lead is prohibited as part of cosmetic compositions in Korea, the European Union, and China. The maximum allow able level of lead is $20 \mathrm{ppm}$ in those jurisdictions, There are no specific rules on other heavy metals, such as cobalt, nickel, and copper [7].It is also reported that those metals can cause allergic contact dermatitis or other skin problems[8,9]. Acceptable limits for heavy metals vary according to the subpopulation of interest (for example, children are more susceptible to heavy metal toxicity than adults). Assessment of dermal absorption by a single component in a cosmetic product is complex and depends on factors such as the concentration in the product, the amount of product applied, the length of time left on the skin and the presence of emollients and penetration enhancers in the cosmetic product. Given this complexity and the lack of well-conducted dermal absorption studies incorporating these factors, determination of heavy metal limits in cosmetics based on human health risk alone is a challenge [10]. It was disclosed in a report that $100 \%$ of all cosmetics product tested positive for nickel and over $90 \%$ tested positive for both lead and beryllium [11]. Heavy metals are found naturally in the environment in rocks, soil and water; therefore they exist in the manufacture of pigments and other raw materials in all industries including the cosmetics industry. 
Some of these metals have been used as cosmetic ingredients in the past. Examples include the preservative thiomersal (mercury), the progressive hair dye lead acetate and a number of tattoo pigments such as red cinnabar mercuric sulfide, Since the issue of heavy metals as deliberate cosmetic ingredients have been addressed, attention is turned to the presence of these substances as impurities. The metals of primary toxicological concern in cosmetics are lead, arsenic, cadmium, mercury and antimony [12]. Dermal exposure is expected to be the most significant route for cosmetic products since the majority of cosmetics are applied to the skin. Dermal absorption of heavy metals is fairly minimal, with absorption of individual elements influenced by a number of factors in clouding physical-chemical properties of the mixtures. Oral exposure can occur for cosmetics used in and around the mouth as well as from Hand to mouth contact after exposure to cosmetics containing heavy metal impurities. However, inhalation exposure is typically considered to be negligible [13].At higher concentrations, heavy metals have been shown to have negative effects. Cancerous breast biopsies show higher accumulations of nickel, chromium, cadmium, mercury and lead than non-cancerous biopsies and several metals act like estrogen in the presence of some breast cancer cells. Lead, which may be an impurity, is a proven neurotoxin linked to learning, language and behavioral problems [14]. It has also been linked to miscarriage, reduced fertility in men and women, hormonal changes, menstrual irregularities and delays in puberty onset in girls. At puberty, boys developing testes may be particularly vulnerable to lead. Pregnant women and young children are also vulnerable because lead crosses the placenta and may enter the fetal brain [15]. Mercury is linked to nervous system toxicity, as well as reproductive, immune and respiratory toxicity. Mercury is also found in thiomersal, which is a mercury-based preservative. Mercury is particularly hazardous during fetal development and is readily absorbed by the skin. Neither mercury nor thiomersal are highly common as direct ingredients or impurities, but the high toxicity of this metal means that the presence of mercury in any cosmetic is a concern. Other heavy metals show a similar tendency to be toxic $[16,17]$.

\section{Materials And Methods}

Forty cosmetics in the form eye shadow were bought from various stores and shops in different locations in Baghdad, Iraq.

Preparation of standard solutionsStandard solutions of Lead, Cadmium, Copper, and Nickel were prepared from 1000 ppm Standard Stock Solution of GFS Fishers' AAS Reference Standard. These stock solutions were serially diluted to give concentrations of $0.5,1.5$, and $2 \mathrm{ppm}$ for lead while $0.5,1,1.5$, and $2 \mathrm{ppm}$ for cadmium, and $0.5,1,1.5,2$ for copper, and $0.5,1,1.5,2$ nickel standards.

\section{Preparation and digestion of samples}

All the sample were digested using the same method [18],0.5 gm of each sample was carefully pipette into digestion test tube and $10 \mathrm{ml}$ of digested acid(3:1 $\left.\mathrm{HCl}: \mathrm{HNO}_{3}\right)$ Was added to each sample. This was placed on the hot plate as $30 \mathrm{~min}$. On completion of digestion, the digested samples were allowed to cool to room temperature and made up to $50 \mathrm{ml}$ with distilled water, then the samples were filtered(use wit man filter paper No.41) and of each samples were transferred into volumetric flask for analysis by flame atomic absorption spectroscopy(FAAS).

\section{Result}

Determined metal concentration in each cosmetic, The spectrophotometer automatically determined the concentration of each metal present in the samples by extra plating the calibration curve in parts per million (Table1).

Table (1) metal concentration in each cosmetic

\begin{tabular}{|c|c|c|c|c|c|c|}
\hline NO. & Sample & Color & $\mathrm{Cu}$ & $\mathrm{Ni}$ & $\mathrm{Pb}$ & $\mathrm{Cd}$ \\
\hline 1 & Without & Pink & 1.2808 & 0.4123 & 9.91 & Nil \\
\hline 2 & & Blue & 19.102 & 0.3142 & 9.54 & 0.5428 \\
\hline 3 & & White & 2.2439 & 0.7428 & 18.975 & Nil \\
\hline 4 & & Yellow & 0.6111 & 0.357 & 7.425 & Nil \\
\hline 5 & & Ginger & 0.2289 & 0.5123 & 5.657 & Nil \\
\hline 6 & & Gray & 0.4054 & 1 & 6 & 0.7321 \\
\hline 7 & & Purple & 0.3570 & 0.4 & 8.60 & 1.5857 \\
\hline 8 & & Green light & 4.4323 & 0.7 & 25.57 & 2.65 \\
\hline 9 & Meilaiye & Pink & 10.7 & 0.510 & 7.5 & Nil \\
\hline 10 & & Gray & 6.566 & 0.732 & 6.8 & Nil \\
\hline 11 & & White & 1.792 & 0.25 & 2.14 & 0.207 \\
\hline 12 & & Violets & 2 & Nil & 4.18 & 0.085 \\
\hline 13 & & Black & 1.71 & 0.035 & 19 & 0.157 \\
\hline 14 & Ever beauty & Gray & 3.039 & Nil & 4.8 & 1.035 \\
\hline
\end{tabular}


Determination of heavy metals in some cosmetics available in locally markets

\begin{tabular}{|c|c|c|c|c|c|c|}
\hline 15 & & Dark Red & 7.1651 & 1.42 & 4.18 & 0.382 \\
\hline 16 & & Blue & 9.35 & 1.132 & 24.6 & 0.090 \\
\hline 17 & & Pink & 2.41 & 0.313 & 2.92 & 0.909 \\
\hline 18 & & Green & 14.05 & 1.717 & 5.21 & 1.55 \\
\hline 19 & & Gray & 0.86 & Nil & 5.22 & Nil \\
\hline 20 & & Brown & 1.946 & Nil & 1.46 & 0.132 \\
\hline 21 & & Dark Red & 8.315 & 12.42 & 1.357 & 0.135 \\
\hline 22 & & Gold & 6.46 & 0.035 & 3.97 & 0.646 \\
\hline 23 & AlKiss & Sooty Black & 1.42 & 3.17 & 3.97 & 0.15 \\
\hline 24 & & Orange & 0.6545 & 8.57 & 3.76 & 0.092 \\
\hline 25 & & White & 13.9 & 0.071 & 1.25 & 0.121 \\
\hline 26 & Without & Violate & 3.305 & Nil & 3.75 & 0.107 \\
\hline 27 & & Pink & 2.285 & 0.392 & 3.44 & 0.126 \\
\hline 28 & & Black & 2.05 & 0.83 & 17.13 & 0.28 \\
\hline 29 & Baxi & Orange & 1.32 & 1.132 & 2.31 & 0.635 \\
\hline 30 & & Yellow & 0.485 & 0.525 & Nil & 1.585 \\
\hline 31 & & Gray & 0.428 & 3.24 & 1.88 & 5 \\
\hline 32 & & Green & 1.23 & 2.85 & 1.875 & 3.06 \\
\hline 33 & & Blue & 0.421 & 0.475 & Nil & 7.4 \\
\hline 34 & & Violet & 0.346 & 0.84 & Nil & 6.40 \\
\hline 35 & & White & 0.27 & 0.475 & Nil & 6.41 \\
\hline 36 & & Pink & 0.39 & 0.55 & Nil & 0.98 \\
\hline 37 & & Ginger & 0.085 & 0.071 & Nil & 0.96 \\
\hline 38 & Role Rose & Black & 0.092 & 6.871 & 12.54 & 1.22 \\
\hline 39 & & Purple & 0.135 & 0.625 & 1.46 & 3.60 \\
\hline 40 & & Gray & Nil & 0.403 & 0.210 & 8.14 \\
\hline
\end{tabular}

\section{Discussion}

Cosmetics are seen as one of the most important sources of releasing heavy metals into the environment and the human biological system. Following such observation, there is an increasing need to investigate the concentration of toxic metals in some commonly used cosmetic products. It is known for instance that high doses of heavy metals can be deadly and that even long-term exposure to low levels of heavy metals can cause certain cancers. There is also a growing concern about the physiological and behavioral effects of toxic metals on human population in general. For instance, the toxicity of lead at high concentrations of exposure is well documented but a major concern in recent time is the possibility that continual exposure to even relatively low levels of these toxic metals in cosmetic products may pose potential health risks [18]. The possibility of skin allergy and contact dermatitis may increase due to the presence of heavy metals in cosmetics. In this study, the different cosmetic products were tested for the presence of Copper, cadmium, lead, and nickel. Table 1 shows the concentrations of heavy metal for each of the eye shadow in ppm. The heavy metals found in the products tested are categorized as unintentional contaminants. These metals are not intentionally added to the formulation but are simply impurities in the product and are therefore not required to be listed on the labels. An impurity is a sub-stance not intentionally added to a product, but rather is either a byproduct of the manufacturing process, formed by the breakdown of ingredients, or an environmental contaminant of raw ingredients[19].The latter is the case for heavy metals, as their persistence in the environment and their natural presence in rocks, soil, and water cause them to be present in the manufacture of pigments and other raw materials used in various industries, including cosmetics. Manufacturers are required to take care to remove these impurities, but time is money and since guidelines are so laid-back, only very few manufacturers remove these heavy metals from the final product [20]. Although the presence of the toxic metals in all the samples were in trace amount, the slow release of these metals into the human system may be harmful to the biological system if allowed to accumulate over time. These metals could accumulate in the body organs due to their long half life. It has been reported that these metals interfere with essential nutrients of similar oxidation states such as calcium and zinc [21].The metals analyzed in this study are not listed as ingredients on any of the products. Due to a lack of manufacturer testing and regulatory oversight, it is possible that the companies are not even aware that the products are contaminated with these toxic metals. These contaminants are likely to have gained entrance into the cosmetic products when poor-quality ingredients are used. Most likely, these toxic metals could have been contaminants from one or more of the inorganic base materials used in the manufacturing processes. Since these toxic metals are found in various environments, manufacturers are advised to test the raw ingredients for the presence of these toxic metals before their products are assembled into final products in order to track the origin of these contaminants. 


\section{Conclusion}

In the present study, cadmium, lead, Copper and nickel were determined in various brand of eye shadow. From the results, the toxic metals were present in low quantities. It is feared how-ever that the continuous use of cosmetic products contaminated with such heavy metals may however cause slow release of these metals into the human body and cause harmful effects to the consumers over time. Extensive use of such products should be avoided until the situation is adequately addressed.

[1]. ReedS (2007) .Cosmetics and your health. USA Department of Health and Human Services: 22-25.

[2]. Oyedeji FO, HassanGO,delekeBB (2011). Hydroquinone and heavy metal levels in cosmetics marketed inNigeria, Trends Appl. Sci.Res6:622-639.

[3]. Rao N, Prathiba S (1998). Cosmetics and personal care products,ElsevierInc: $380-382$

[4]. Peter AL, Viraraghavan T Thallium (2005). A review of public health and environmental concerns. Environ. Int. $31(4)$ : 493-501.

[5]. Nesterenko PN, Jones P (1997). Single-columnmethod of chelation ion chromatographyor theanalysisof tracemetalsin complexsamplesJ.ChromatogAr, 770: 129-135.

[6]. Sainio E, Jolanki R, Hakala E,Kanerva L (2000). Metals and arsenicin eyeshadows contactdermatitis, 42: 5-10.

[7]. Hostynek j (2000).Chromium, Cobalt, Copperand Iron: Metals in personalcare products, DermatologVicie W, 115: 52-65.

[8]. Maibach M, Menne T (1989).Nickel and the Skin: ImmunoloagnydToxicology (CRC Press, ocaRAton, FL: 223.

[9]. Kerosuo K,Kullaa,Kerosuo E,Kanerva L,Hensten A, Petersen (1996). Nickel allergy in adolescents in relation to orthodontictreatmentandpiercingof ears a, m.J. OrthodonD.entofacO. Rthoped10(9): 148-154.,

[10]. Adepoju-Bello AA,OguntibejuOO, AdebisiRA,OkpalaN,CokerHAB (2012). Evaluation of the concentration of toxic metals in cosmetic products in Nigeria. African J.Biotechnology, 11 (97): 16360-16364.

[11]. Health Canada (2011). Toxic metals found in make-up cosmetics. A report released by Environmental Defiance: 23-26.

[12]. Sainio E, Jolanki R, Hakala E, Kanerva L (2000). Metals and arsenic in eye shadows Contact Derma, 42:5 -10.

[13]. AlSaleh I,AlEnazi S, Shinwari N (2009). RegulateToxicol. Pharmacol, 54: 105-113.

[14]. AyenimoJG, Yusuf AM, AdekunleAS (2010). Heavy Metal Exposure from Personal Care Products. Bulletin of Environmental Contamination and Toxicology, 84(1): 8-14

[15]. Horowitz Y, Greenberg D, Ling G, Lifshitz M, Acrodynia AA(2002). Case report of two siblings. Arch Dis Child 86: 453 -455.

[16]. UNEP (2008). Mercury in products and wastes. Geneva, United Nations Environment Programme, Division of Technology, Industry and Economics, Chemicals Branch. (VL)

[17]. UNEP/WHO (2008). Guidance for identifying populations at risk from mercury exposure. GenevaWorld Health Organization (http://www.who.int/entity/foodsafety/publications/chem/mercury/en/).

[18]. MuhamadDarus, Nasir F,RA, Sumari, SM,Ismail,ZS, Omar,NA(2011). Nurseryschools, Characterization of heavy metal content indoor dust. AsianJ.ofEnviroment-Behaviour Studies,2(6):53-60.

[19]. Ayenimo JG, Yusuf AM, AdekunleAS (2010). Heavy metal exposure from personal care products. Bull Environ. Contam. Toxicol. 84(1): 8-14..

[20]. Health Canada (2011). Toxic metals found in make-up cosmetics. A report released by Environmental Defiance: 23-26.

[21]. Adepoju-Bello AA, Alabi OM (2005). Heavy metals: a review. Nig .J. Pharm. 37:41-45. 